\title{
Влияние предобработки подложки кремния на свойства пленок GaN, выращенных методом хлорид-гидридной газофазной эпитаксии
}

\author{
(C) П.В. Середин ${ }^{1}$, К.А. Барков ${ }^{1}$, Д.Л. Голощапов ${ }^{1}$, А.С. Леньшин ${ }^{1}$, Ю.Ю. Худяков ${ }^{1}$, И.Н. Арсентьев ${ }^{2}$, \\ A.А. Лебедев ${ }^{2}$, Ш.Ш. Шарофидинов ${ }^{2}$, А.М. Мизеров ${ }^{3}$, И.А. Касаткин ${ }^{4}$, Tatiana Prutskij ${ }^{5}$ \\ ${ }^{1}$ Воронежский государственный университет, \\ 394006 Воронеж, Россия \\ ${ }^{2}$ Физико-технический институт им. А.Ф. Иоффе Российской академии наук, \\ 194021 Санкт-Петербург, Россия \\ ${ }^{3}$ Санкт-Петербургский национальный исследовательский Академический университет Российской академии наук, \\ 194021 Санкт-Петербург, Россия \\ ${ }^{4}$ Санкт-Петербургский государственный университет, \\ 199034 Санкт-Петербург, Россия \\ ${ }^{5}$ Instituto de Ciencias, Benemérita Universidad Autónoma de Puebla, \\ 72050 Puebla, Pue., Mexico \\ E-mail: paul@phys.vsu.ru
}

Поступила в Редакцию 6 апреля 2021 г.

В окончательной редакции 15 апреля 2021 г.

Принята к публикации 15 апреля 2021 г.

Сообщается о росте методом хлорид-гидридной газофазной эпитаксии пленки GaN на предварительно обработанных кремниевых подложках $\mathrm{Si}(001)$ через буферный слой $\mathrm{AlN}$. Продемонстрировано, что использование предложенной технологии привело к образованию в подложке $\mathrm{Si}$ переходного субслоя, дальнейший рост на котором обеспечил формирование столбчатых зерен $\mathrm{GaN}$, между которыми находится тонкая прослойка фазы AlN. Эпитаксиальная пленка $\mathrm{GaN}$ имеет низкую величину остаточных напряжений, что нашло свое отражение в интенсивной люминесценции.

Ключевые слова: хлорид-гидридная газофазная эпитаксия, фотолюминесценция, GaN, AlN, Si.

DOI: $10.21883 /$ FTP.2021.08.51144.9660

\section{1. Введение}

Нитриды металлов III группы являются перспективными материалами для изготовления оптических и мощных высокочастотных электронных устройств [1], а наиболее удачным с коммерческой и практической точек зрения для роста этих нитридов является кремниевая подложка [2], обеспечивающая интеграцию отличных оптоэлектронных свойств нитридов и возможностей кремниевой электроники. Однако непосредственный рост $\mathrm{GaN}$ на кремниевых подложках приводит к ряду негативных эффектов, для минимизации которых между подложкой $\mathrm{Si}$ и $\mathrm{A}^{\mathrm{III}} \mathrm{B}^{\mathrm{V}}$ пленкой зачастую выращивают промежуточные слои $\mathrm{AlN} / \mathrm{GaN}$ или буферные слои AlN. B работе [3] с помощью специальной обработки подложки $\mathrm{Si}(100)$ был выращен буферный слой AlN толщиной $\sim 600$ нм, на котором в последующем был получен полуполярный слой $\mathrm{GaN}$ в направлении плоскости (1013). Технологии на основе предварительной подготовки применялись в работах $[4,5]$, а также с введением пористой прослойки - в работах [6,7]. За последние годы было разработано большое число подходов и технологических приемов получения гетероструктур GaN/AlN/Si, среди которых химическое осаждение металлов и органических соединений [4], импульсное лазерное осаждение [5] и молекулярнолучевая эпитаксия [6]. Одним из интересных методов роста $\mathrm{GaN}$ и $\mathrm{AlN}$ слоев на подложках $\mathrm{Si}$ является метод хлорид-гидридной газофазной эпитаксии (ХГФЭ), который хорошо себя зарекомендовал как относительно дешевый способ формирования объемных качественных $\mathrm{A}^{\mathrm{III}} \mathrm{N}$ пленок $[7,8]$.

Поэтому в нашей работе мы исследовали возможность получения методом ХГФЭ пленки $\mathrm{GaN}$, с использованием буферного слоя AIN на предварительно обработанной подложке $\mathrm{Si}(001)$.

\section{2. Материалы и методы исследования}

Для роста использовались положки кремния $\mathrm{Si}(001)$ с разориентацией $3^{\circ}$ к (011), n-типа проводимости (легирование фосфором), удельным сопротивлением 0.3 Ом · см. Эпитаксия проводилась на установке HVPE, состоящей из кварцевого реактора с печью резистивного нагрева с шестью зонами. В качестве реагентов использовался хлористый водород $(\mathrm{HCl})$ и аммиак $\left(\mathrm{NH}_{3}\right)$. В качестве источников использовались металлический алюминий $(\mathrm{Al})$ и галлий $(\mathrm{Ga})$. Транспортирующим газом служил аргон высокой чистоты (Ar - 99.98\%). Перед началом процесса реактор продувался в течение 1 ч в потоке аргона. Выход нагрева на режим роста занимал 2 ч. При достижении ростовой температуры подложки кремния передвигались в ростовую зону и подвергались отжигу в течение 10 мин в потоке аргона. На первом этапе 
осуществлялся рост AlN толщиной 300 нм. При этом поток хлористого алюминия составил $V_{\mathrm{Al}}=200$ мл/мин, а поток аммиака составил $V_{\mathrm{NH}_{3}}=1000$ мл/мин. Суммарный поток по аргону составил порядка $V=3000$ мл/мин. Температура роста составила порядка $T=1100^{\circ} \mathrm{C}$. Временно́й режим роста варьировался от $t=5$ до 20 мин.

Далее осуществлялся рост GaN. Ростовая температура $\mathrm{GaN}$ была в пределе $T=1025-1050^{\circ} \mathrm{C}$. Поток хлористого галлия составил $V_{\mathrm{Ga}}=100 \mathrm{мл/мин.} \mathrm{Поток}$ аммиака $V_{\mathrm{NH}_{3}}=1500$ мл/мин.

Перед эпитаксией кремниевые подложки обрабатывались по следующей схеме. Пластины кипятились в изопропиловом спирте 30 мин, затем перемещались в раствор перекиси водорода с соляной кислотой и деионизованной водой $(2: 1: 7)$, где кипятились 25 мин. После этого происходило травление в растворе плавиковой кислоты с деионизованной водой $(1: 5)$ в течение 2 мин.

Рентгенодифракционный анализ был выполнен при температуре $305 \mathrm{~K}$ с помощью дифрактометра Bruker D8 Discover, работающего в режиме линейной фокусировки с параллельным пучком. Первичный пучок монохроматизирован для получения излучения $\mathrm{Cu} K_{\alpha_{1}} \mathrm{c}$ длиной волны $1.54056 \AA$.

Микроскопические исследования качества гетероинтерфейсов были выполнены на электронном микроскопе Libra 120 Carl Zeiss. Изучение морфологии поверхности проводили с использованием сканирующего зондового микроскопа Femtoscan-001 NT MDT в режиме атомносиловой микроскопии.

Спектры комбинационного рассеяния света (КРС) были получены на конфокальном рамановском микроскопе RamMix 532 со спектральным разрешением $2 \mathrm{~cm}^{-1}$, в диапазоне 200-2000 $\mathrm{cm}^{-1}$. Возбуждение проводилось лазером с длиной волны 532 нм, мощность на образце была $\sim 10-50$ мВт. Сигнал с поверхности образца собирали с использованием объектива $100 \times$.

Спектры люминесценции образцов были получены на установке для измерения фотолюминесценции и оптического отражения Accent RPM Sigma. Исследования проводились при комнатной температуре при возбуждении лазером с длиной волны излучения 266 нм.

\section{3. Экспериментальные результаты и их обсуждение}

\section{1. Рентгенодифракционный анализ}

На рис. 1 представлены результаты рентгенофазового анализа. Из экспериментальных данных видно, что основные высокоинтенсивные рефлексы (0002) и (0004) относятся к вюрцитному $\mathrm{GaN}$, а менее интенсивный рефлекс (0002) связан с эпислоем AlN с вюрцитной структурой. Присутствие на дифрактограмме фактически только лишь максимумов одной базальной серии свидетельствует о монокристаллическом состоянии эпитаксиальной пленки.

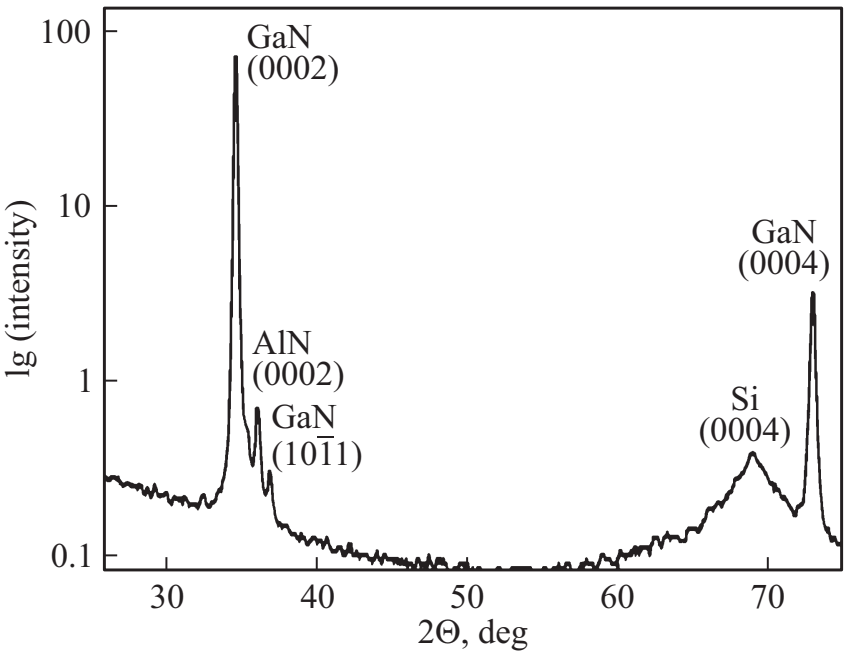

Рис. 1. Обзорная дифрактограмма гетероструктуры GaN/AlN/ $\mathrm{Si}(001)$.

Кроме перечисленных рефлексов, на дифрактограмме присутствует отражение (004) от кремниевой подложки. Низкая интенсивность этого рефлекса является следствием отклонения ориентации подложки $\mathrm{Si}$ от направления [001].

Следует отметить, что на дифрактограмме присутствует низкоинтенсивный рефлекс, который может быть приписан отражению (1011) от GaN. Хорошо известно, что эпитаксиальный рост гексагонального $\mathrm{GaN}$ на подложках кубического $\mathrm{Si}(001)$ приводит к поликристаллическому состоянию пленки нитрида галлия, в то время как использование подложек $\mathrm{Si}(001)$ с отклонением от направления [001] ведет к появлению текстуры [9]. В соответствии с данными работы [10] возникновение рентгеновского отражения может происходить в случае роста полуполярного подслоя $\mathrm{GaN}(10 \overline{1} 1)$ на профилированной подложке $\mathrm{Si}(001)$ с буферным слоем AlN.

\section{2. Спектроскопия $\mathrm{KPC}$}

Многократно было показано [11], что метод спектроскопии КРС весьма успешно используется для анализа и оценки структурного качества эпитаксиальных тонких пленок, выращенных на подложках с различной ориентацией. Наличие такой информации является важным с точки зрения практических применений низкоразмерных структур в микро- и оптоэлектронных устройствах, так как фононы влияют на скорость релаксации возбужденных электронов и на подвижность носителей заряда.

На рис. 2 представлен спектр КРС гетероструктуры $\mathrm{GaN} / \mathrm{AlN} / \mathrm{Si}(001)$. Наиболее интенсивный максимум в спектрена частоте $520 \mathrm{~cm}^{-1}$ относится к длинноволновому поперечному оптическому фонону кремниевой подложки.

Следует отметить, что кроме интенсивных максимумов в спектре $\mathrm{Si}$ присутствуют моды с низкой 


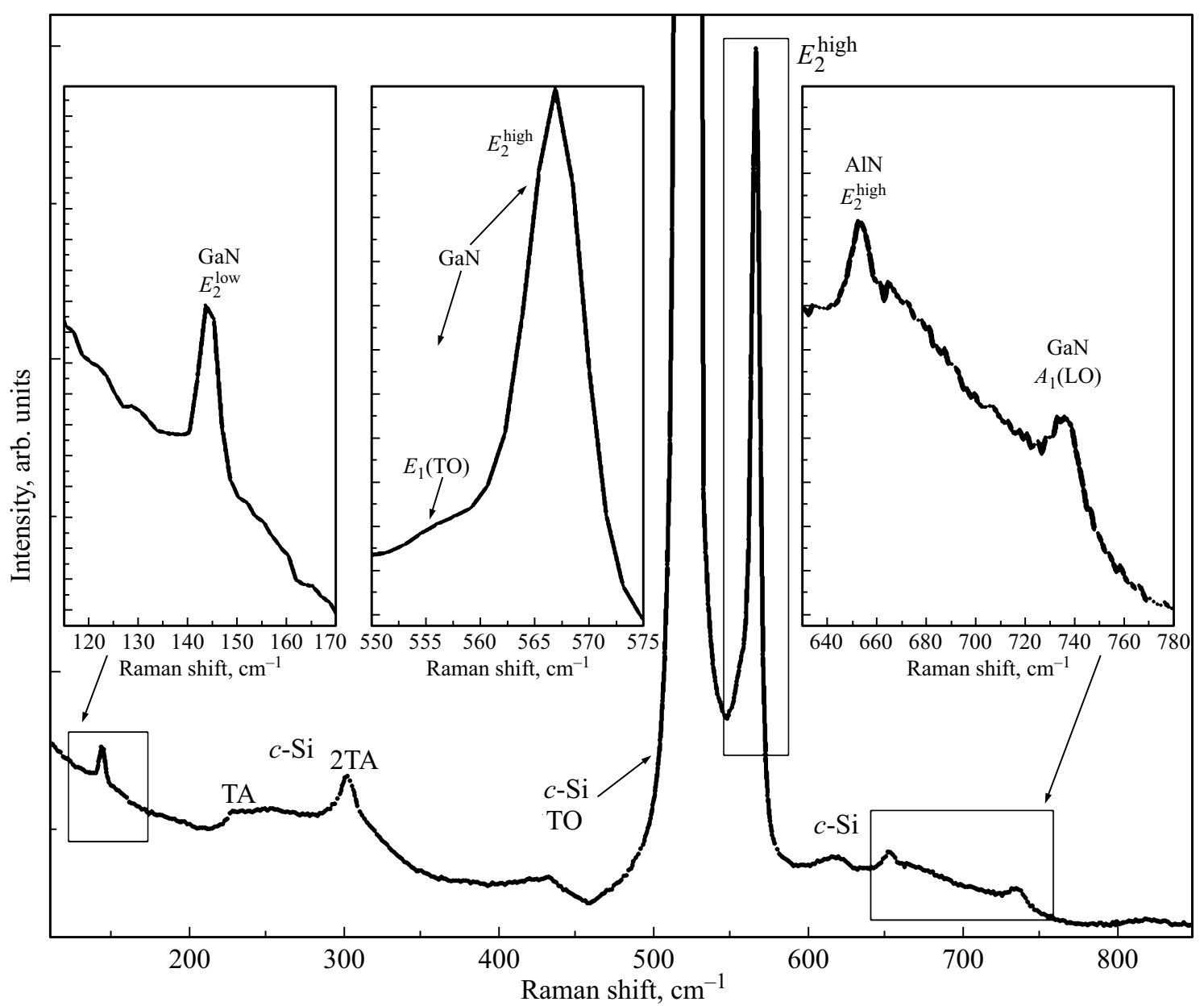

Рис. 2. Спектр КРC пленки GaN/AlN, выращенной на подложке $\mathrm{Si}(001)$. На вставках в увеличенном масштабе представлены области $120-170,550-575$ и $630-780 \mathrm{~cm}^{-1}$.

интенсивностью, связанные с поперечными акустическими фононами первого (ТА $\sim 240 \mathrm{~cm}^{-1}$ ) и второго $\left(2 \mathrm{TA} \sim 300 \mathrm{~cm}^{-1}\right)$ порядков [12], а также с продольными акустическими фононами LA $\left(\sim 300 \mathrm{~cm}^{-1}\right)$ [12].

В спектре КРС эпитаксиальной пленки наблюдаются четыре характерных линии, наличие которых указывает на формирование слоя $\mathrm{GaN}$ вюрцитной сингонии. Эти линии относятся к фононам симметрии $E_{2}^{\text {low }}(\mathrm{GaN})$ $\left(143 \mathrm{~cm}^{-1}\right), \quad E_{1}(\mathrm{TO})(\mathrm{GaN}) \quad\left(555 \mathrm{~cm}^{-1}\right), \quad E_{2}^{\text {high }}(\mathrm{GaN})$ $\left(566.8 \mathrm{~cm}^{-1}\right), \quad A_{1}(\mathrm{LO})(\mathrm{GaN}) \quad\left(736 \mathrm{~cm}^{-1}\right)$. Максимум в спектре около $653 \mathrm{~cm}^{-1}$ соответствует моде $E_{2}^{\text {high }}(\mathrm{AlN})$, самой сильной из разрешенных мод в пленках вюрцитного AIN [13].

Для моды $E_{2}^{\text {high }}(\mathrm{GaN})$ ширина линии на половине ее высоты (FWHM) составляет $\sim 6.2 \mathrm{~cm}^{-1}$, что указывает на хорошее кристаллическое качество слоя $\mathrm{GaN}$. При этом хорошо известно, что FWHM линии КРС $A_{1}(\mathrm{LO}) \mathrm{GaN}$ лучше характеризует процесс комбинационного рассеяния света в эпитаксиальном слое $\mathrm{GaN}$ с точки зрения времени жизни фононов.

Эксперимент достоверно показывает, что частотное смещение фононной моды $E_{2}$ (high) в спектре КРС слоя
$\mathrm{GaN}$ и аналогичной моды для AlN позволяет определить величину деформации (двухосного напряжения) в эпитаксиальном слое на основе соотношения $[11,14]$

$$
\sigma_{x x}=\Delta \omega / K
$$

где $\sigma-$ величина двухосного напряжения (в ГПа), a $\Delta \omega=\omega_{0}-\omega-$ сдвиг линии фонона $E_{2}$ (high) GaN или AIN относительно его положения $\left(\omega_{0}\right)$ в объемном недеформированном кристалле.

Здесь $K$ является коэффициентом преобразования двухосного напряжения в частотный сдвиг, который для $\mathrm{GaN}$ имеет значение $2.77\left(\mathrm{~cm}^{-1} \cdot \Gamma \mathrm{Ia}^{-1}\right)[4,15]$, а для AlN его значение равно 3.7 [13].

Из соотношения (1) следует, что если линия в спектре смещается в низкочастотную область относительно положения максимума для полностью ненапряженной пленки, то это указывает на наличие растягивающих напряжений, а смещение в высокочастотную область соответствует сжимающим напряжениям. Значения частотного положения моды $E_{2}$ (high) в ненапряженном GaN $567.6 \mathrm{~cm}^{-1}$ [16] и ненапряженном AlN $657.4 \mathrm{~cm}^{-1}$ [13]. Расчет показывает, что величина напряжения для слоя 

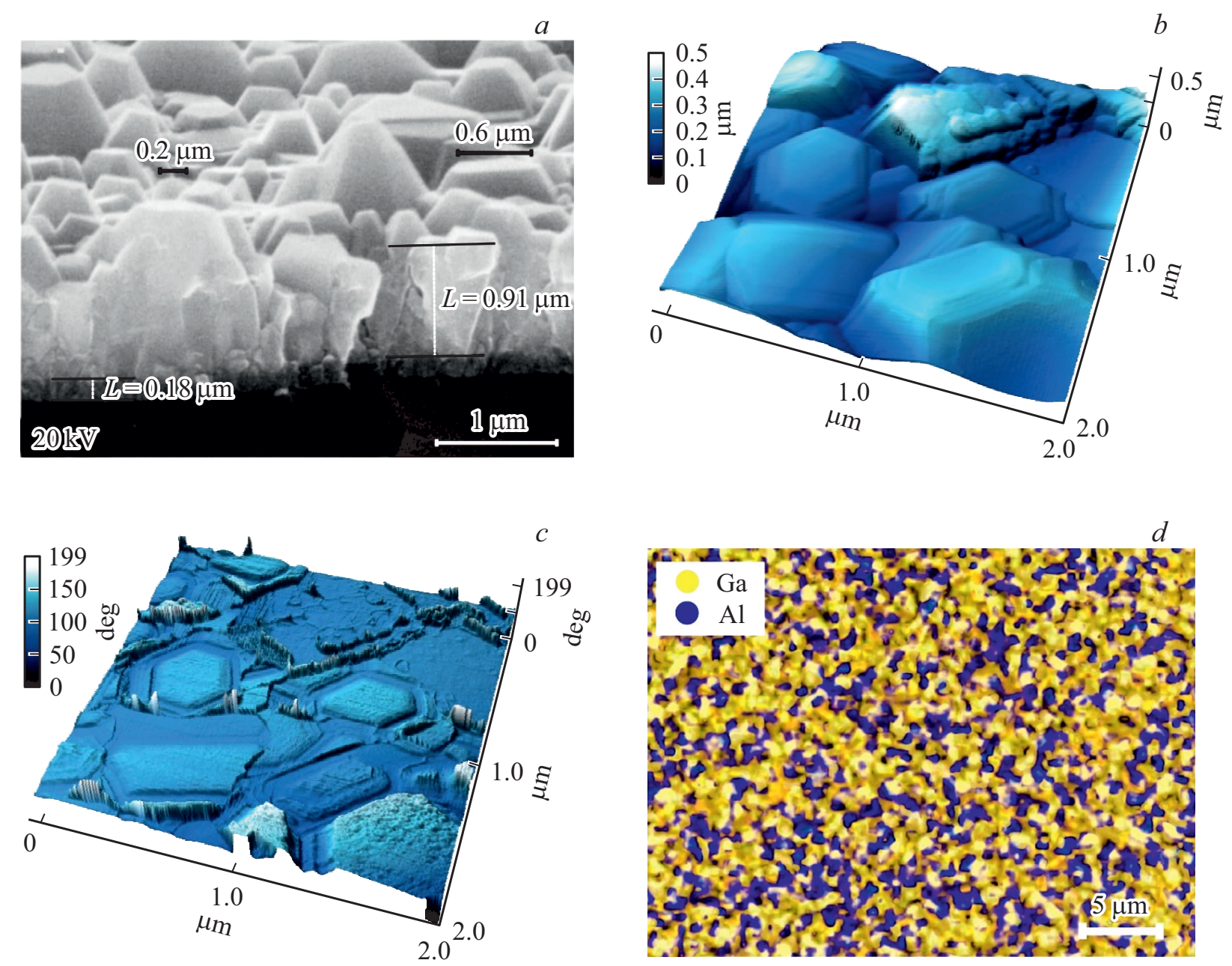

Рис. 3. Данные микроскопических исследований гетероструктуры $\mathrm{GaN} / \mathrm{AlN} / \mathrm{Si}(001)$. (a) - изображение скола структуры, полученное методом сканирующей электронной микроскопии. Морфология поверхности эпитаксиального слоя GaN по данным атомно-силовой микроскопии в 3D режиме $(b)$ и режиме фазового контраста $(c)$. Данные энергодисперсионного микроанализа выбранного участка поверхности образца $(d)$.

$\mathrm{GaN} \sigma=289$ МПа находится ниже характерного предела прочности на разрыв $400 \mathrm{MPa}$ при растягивающих напряжениях [17]. При этом значение напряжения в слое AlN в соответствии с расчетом находится на уровне $\sigma=1.2$ ГПа. Полученные значения для двухос-

Результаты спектроскопии КРС и ФЛ измерений

\begin{tabular}{c|c|c}
\hline \multirow{2}{*}{$\begin{array}{c}\text { Компонент } \\
\text { гетероструктуры }\end{array}$} & \multicolumn{2}{|c}{ Остаточные напряжения, $\sigma$} \\
\hline & Спектроскопия КРС & ФЛ спектроскопия \\
\hline \multirow{2}{*}{$\mathrm{Si}$} & - & - \\
\hline \multirow{2}{*}{$\mathrm{GaN}$} & $289 \mathrm{MПа}$ & $308 \mathrm{MПа}$ \\
\cline { 3 - 3 } & & - \\
\hline \multirow{2}{*}{$\mathrm{AlN}$} & 1.2 ГПа & - \\
\cline { 2 - 3 } & - & -
\end{tabular}

ного напряжения в эпитаксиальных слоях представлены в таблице. Отметим, что величина обнаруженных нами частотных сдвигов хорошо согласуется с теорией, представленной в работах [18-20].

Следует отметить, что характерное двухосное напряжение $\sigma$ в $\mathrm{GaN}$ эпитаксиальном слое, выращенном методом плазменной молекулярно-лучевой эпитаксии через субслой $\mathrm{AlN}$, находилось на уровне $\sigma \sim 400 \mathrm{MPa}$ [2], что сопоставимо с полученными нами результатами.

\section{3. Микроскопические исследования}

Результаты электронной микроскопии, представленные на рис. 3, показали, что эпитаксиальная пленка GaN/AlN состоит из столбчатых зерен высотой $\sim 1$ мкм (см. рис. 3,a), имеющих небольшую разориентацию относительно направления роста. Из данных хорошо видно, что под эпислоем методом предобработки исходной кремниевой пластины сформирован тонкий 

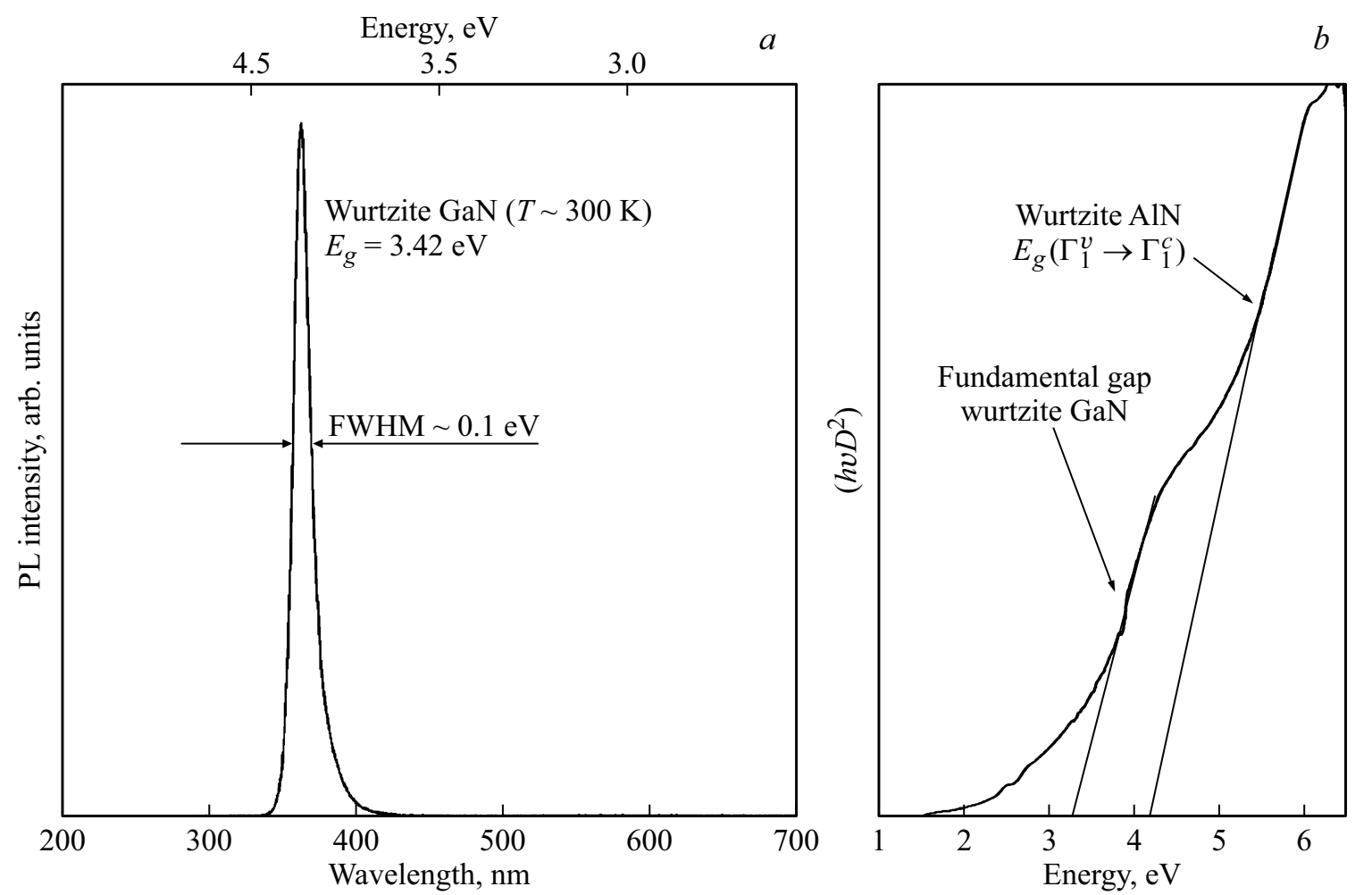

Рис. 4. Результаты оптических исследований. Спектр фотолюминесценции гетероструктуры GaN/AlN/Si(001) (a), зависимость $(D h v)^{2}$ от энергии квантов для GaN/AIN пленки, выращенной на $\operatorname{Si}(001)(b)$.

( 170-200 нм) переходной слой, который в соответствии с литературными данными $[21,22]$ и нашими предыдущими работами представляет собой структурированную поверхность кремния $[9,23]$

Морфология поверхности эпитаксиальной пленки $\mathrm{GaN}$ была исследована методом атомно-силовой микроскопии (ACM) в контактном режиме (рис. $3, b)$, а также в режиме фазового контраста (рис. 3,c). Видно, что поверхность пленки $\mathrm{GaN}$ образована крупными столбчатыми блоками с латеральными размерами $500 \mathrm{Hм}$, что характерно для высокотемпературного эпитаксиального двумерного роста, при котором происходит коалесценция островков кристаллитов из-за усиленной миграции поверхностных адатомов. Более того, как следует из данных фазового контраста (рис. 3,c), между зернами основной фазы $\mathrm{GaN}$ существует тонкая прослойка другой фазы. Эти данные подтверждают исследования выбранного участка поверхности образца методом энергодисперсионного микроанализа (см. рис. $3, d$ ).

\section{4. Оптические исследования}

Особенности оптических свойств в УФ диапазоне ХГФЭ гетероструктур GaN/AlN/Si(100) были изучены с использованием фотолюминесцентной спектроскопии и апробированной нами методики съемки на отражение [24-27].
Экспериментальный спектр ФЛ, представленный на рис. $4, a$, демонстрирует высокоинтенсивную линию излучения, наблюдаемую при комнатной температуре с возбуждением лазером 266 нм. Этот спектральный максимум может быть приписан экситону, связанному с нейтральным донором, расположен $\sim 362$ нм $(3.422$ эВ) и по своей величине совпадающий с оптической шириной запрещенной зоны $\mathrm{GaN}$.

Хорошо известно [28], что для $\mathrm{GaN}$ ширина запрещенной зоны $E_{g}(\mathrm{GaN})$ зависит от величины внутренних напряжений, приложенных к эпитаксиальному слою, и может быть описана с использованием следующего соотношения:

$$
E_{g}(\mathrm{GaN})=3.4285+0.0211 \sigma
$$

где $\sigma$ - двухосное напряжение в эпитаксиальной пленке.

Ширина запрещенной зоны в недеформированном $\mathrm{GaN} 3.43 \pm 0.005$ эВ при $290 \mathrm{~K}[29]$.

Расчет показывает, что энергетический сдвиг $(\sim 0.0065$ эB $)$ полосы фотолюминесценции эпитаксиального слоя $\mathrm{GaN}$ относительно положения для недеформированного кристалла обусловлен остаточными напряжениями $\sim 308 \mathrm{MПа,} \mathrm{что} \mathrm{находится} \mathrm{в} \mathrm{хорошем} \mathrm{со-}$ ответствии с данными спектроскопии КРС (см. таблицу).

Что касается особенностей в спектре поглощения пленки GaN/AlN, то, как известно, прозрачность слоя является предпосылкой для получения оптимального 
светового потока и, следовательно, производительности устройства. Ввиду малой толщины эпислоя GaN/AlN, сформированного на объемной подложке, информация об особенностях оптического поглощения в УФ-диапазоне пропускания-отражения была получена на основе записи спектров пропускания-отражения при большом угле падения электромагнитного излучения на образец. Далее с целью выявления механизмов оптического поглощения в эпитаксиальном слое спектры пропускания-отражения были пересчитаны в спектры поглощения с использованием программы OPUS 7.5 Bruker с использованием соотношений Крамерса-Кронига [30].

В итоге была построена и визуализирована зависимость $(D h v)^{2}$ от энергии квантов (см. рис. 4,b), где $D-$ оптическая плотность. Графический анализ этих данных позволил выявить участки с линейной зависимостью $(D h v)^{2}$ от энергии квантов. Линейная экстраполяция данных участков к нулевому значению позволяет определить энергию прямых разрешенных переходов, характерных для эпислоя. Из полученных данных следует наличие двух прямых переходов в эпитаксиальном слое. Первый из них с энергией $\sim 3.34$ эВ является переходом $E_{g}\left(\Gamma_{1}^{v} \rightarrow \Gamma_{1}^{c}\right)$ и совпадает по величине с краем фундаментального поглощения в тонких пленках $\mathrm{GaN}$ с учетом температурного фактора [31]. Второй переход с энергией 4.24 эВ может быть приписан вюрцитному AlN с ориентированным ростом [32,33] или ориентированным ростом на $m$-плоскости [34].

\section{4. Заключение}

В настоящей работе мы сообщили о росте пленки $\mathrm{GaN}$ методом ХГФЭ на предварительно обработанных кремниевых подложках $\mathrm{Si}(001)$ с отклонением $3^{\circ}$ к плоскости (011) и использованием буферного слоя AlN.

Мы продемонстрировали, что использование предложенной технологии привело к образованию на поверхности подложки $\mathrm{Si}$ переходного субслоя, дальнейший рост на котором обеспечил формирование столбчатых зерен $\mathrm{GaN}$, между которыми находится тонкая прослойка фазы AlN. При этом поверхность зерен GaN со средними латеральными размерами $\sim 500$ нм имеет разориентацию относительно направления роста, заданного подложкой. Эпитаксиальная пленка $\mathrm{GaN}$ имеет низкую величину остаточных напряжений, определенных на основе рамановской и фотолюминесцентной спектроскопии, что нашло свое отражение в интенсивной люминесценции.

Полученные данные послужат важным материалом для понимания основ физики наногетероструктур $\mathrm{GaN} / \mathrm{AlN} / \mathrm{Si}$, способствуя их потенциальному применению в оптоэлектронике.

\section{Благодарности}

Рентгеновские исследования были выполнены с привлечением оборудования ресурсного центра „Рентге- нодифракционные методы исследования“ Санкт-Петербургского государственного университета.

\section{Финансирование}

The study was financially supported by the Russian Science Foundation (grant № 19-72-10007). Pavel Seredin carried out his part of the study with the support from the Ministry of Science and Higher Education of Russian Federation (grant № FZGU-2020-0036) under the State assignment to higher school institutions.

Технология получения гетероструктур GaN/AlN/ $\mathrm{Si}(100)$ была выполнена в рамках государственного задания ФТИ им. А.Ф. Иоффе.

\section{Конфликт интересов}

Авторы заявляют об отсутствии конфликта интересов.

\section{Список литературы}

[1] Y. Feng, V. Saravade, T.-F. Chung, Y. Dong, H. Zhou, B. Kucukgok, I.T. Ferguson, N. Lu. Sci. Rep., 9, 10172 (2019). doi: 10.1038/s41598-019-46628-4

[2] L.S. Chuah, S.M. Thahab, Z. Hassan. J. Nonlinear Opt. Phys. Amp Mater., (2012). doi: 10.1142/S0218863512500142

[3] V.N. Bessolov, Yu.V. Zhilyaev, E.V. Konenkova, N.K. Poletaev, Sh. Sharofidinov, M.P. Shcheglov. Techn. Phys. Lett., 38, 9 (2012). doi: 10.1134/S1063785012010051

[4] S. Choi, E. Heller, D. Dorsey, R. Vetury, S. Graham. J. Appl. Phys., 113, 093510 (2013). doi: 10.1063/1.4794009

[5] W. Wang, W. Yang, Z. Liu, Y. Lin, S. Zhou, H. Qian, H. Wang, Z. Lin, S. Zhang, G. Li. CrystEngComm, 16, 8500 (2014). doi: 10.1039/C4CE00948G

[6] H. Xin Jing, C.A. Che Abdullah, M.Z. Mohd Yusoff, A. Mahyuddin, Z. Hassan. Results Phys., 12, 1177 (2019). doi: 10.1016/j.rinp.2018.12.095

[7] T. Yamane, F. Satoh, H. Murakami, Y. Kumagai, A. Koukitu. J. Cryst. Growth, 300, 164 (2007). doi: 10.1016/j.jcrysgro.2006.11.009

[8] J. Hu, H. Wei, S. Yang, C. Li, H. Li, X. Liu, L. Wang, Z. Wang. J. Semicond., 40, 101801 (2019). doi: 10.1088/16744926/40/10/101801

[9] P.V. Seredin, A.S. Lenshin, D.S. Zolotukhin, I.N. Arsentyev, D.N. Nikolaev, A.V. Zhabotinskiy. Phys. B Condens. Matter, 530, 30 (2018). doi: 10.1016/j.physb.2017.11.028

[10] V. Bessolov, A. Zubkova, E. Konenkova, S. Konenkov, S. Kukushkin, T. Orlova, S. Rodin, V. Rubets, D. Kibalov, V. Smirnov. Phys. Status Solidi B, 256, 1800268 (2019). doi: 10.1002/pssb.201800268

[11] P.V. Seredin, A.V. Glotov, E.P. Domashevskaya, I.N. Arsentyev, D.A. Vinokurov, I.S. Tarasov, I.A. Zhurbina. Semiconductors, 44, 184 (2010). doi: 10.1134/S1063782610020089

[12] P.G. Spizzirri, J.-H. Fang, S. Rubanov, E. Gauja, S. Prawer. ArXiv10022692 Cond-Mat. (2010).

[13] V. Lughi, D.R. Clarke. Appl. Phys. Lett., 89, 241911 (2006). doi: $10.1063 / 1.2404938$

[14] Y. Zeng, J. Ning, J. Zhang, Y. Jia, C. Yan, B. Wang, D. Wang. Appl. Sci., 10, 8814 (2020). doi: 10.3390/app10248814 
[15] Y. Dai, S. Li, H. Gao, W. Wang, Q. Sun, Q. Peng, C. Gui, Z. Qian, S. Liu. J. Mater. Sci. Mater. Electron., 27, 2004 (2016). doi: 10.1007/s10854-015-3984-1

[16] A.H. Park, T.H. Seo, S. Chandramohan, G.H. Lee, K.H. Min, S. Lee, M.J. Kim, Y.G. Hwang, E.-K. Suh. Nanoscale, 7, 15099 (2015). doi: 10.1039/C5NR04239A

[17] S.A. Nikishin, N.N. Faleev, V.G. Antipov, S. Francoeur, L.G. de Peralta, G.A. Seryogin, M. Holtz, T.I. Prokofyeva, S.N.G. Chu, A.S. Zubrilov, V.A. Elyukhin, I.P. Nikitina, A. Nikolaev, Y. Melnik, V. Dmitriev, H. Temkin. MRS Internet J. Nitride Semicond. Res., 5, 467 (2000). doi: $10.1557 / \mathrm{S} 1092578300004658$

[18] M.R. Correia, S. Pereira, E. Pereira, J. Frandon, E. Alves. Appl. Phys. Lett., 83, 4761 (2003). doi: 10.1063/1.1627941

[19] R.J. Briggs, A.K. Ramdas. Phys. Rev. B, 13, 5518 (1976). doi: 10.1103/PhysRevB.13.5518

[20] L. Teng, R. Zhang, Z.-L. Xie, T. Tao, Z. Zhang, Y.-C. Li, B. Liu, P. Chen, P. Han, Y.-D. Zheng. Chin. Phys. Lett., 29, 027803 (2012). doi: 10.1088/0256-307X/29/2/027803

[21] Y.-K. Lin, Y.-S. Chen, C.-H. Hsueh. Results Phys., 12, 244 (2019). doi: 10.1016/j.rinp.2018.11.051

[22] M. Arias, M. Briceño, A. Marzo, A. Zárate. J. Chil. Chem. Soc., 64, 4268 (2019). doi: $10.4067 / \mathrm{s} 0717-97072019000104268$

[23] P.V. Seredin, A.S. Lenshin, D.S. Zolotukhin, I.N. Arsentyev, A.V. Zhabotinskiy, D.N. Nikolaev. Phys. E Low-Dim. Syst. Nanostructures, 97, 218 (2018). doi: 10.1016/j.physe.2017.11.018

[24] V.A. Volodin, M.D. Efremov, V.Ya. Prints, V.V. Preobrazhenskii, B.R. Semyagin, A.O. Govorov. J. Exp. Theor. Phys. Lett., 66, 47 (1997). doi: 10.1134/1.567481

[25] P.V. Seredin, A.S. Lenshin, V.M. Kashkarov, A.N. Lukin, I.N. Arsentiev, A.D. Bondarev, I.S. Tarasov. Mater. Sci. Semicond. Process., 39, 551 (2015). doi: 10.1016/j.mssp.2015.05.067

[26] P.V. Seredin, V.M. Kashkarov, I.N. Arsentyev, A.D. Bondarev, I.S. Tarasov. Phys. B Condens. Matter, 495, 54 (2016). doi: 10.1016/j.physb.2016.04.044

[27] P.V. Seredin, A.S. Lenshin, D.L. Goloshchapov, A.N. Lukin, I.N. Arsentyev, A.D. Bondarev, I.S. Tarasov. Semiconductors, 49, 915 (2015). doi: 10.1134/S1063782615070210

[28] Y.-T. Chiang, Y.-K. Fang, T.-H. Chou, F.-R. Juang, K.-C. Hsu, T.-C. Wei, C.-I. Lin, C.-W. Chen, C.-Y. Liang. IEEE Sens. J., 10, 1291 (2010). doi: 10.1109/JSEN.2009.2037310

[29] P.P. Paskov, B. Monemar. In Handb.: GaN Semicond. Mater. Devices, ed. by W. Bi, H. Kuo, P.-C. Ku, B. Shen, 1st edn (CRC Press, Boca Raton, Taylor \& Francis, CRC Press, 2017. | Ser:: Series in Optics and Optoelectronics, 2017) p. 87. doi: 10.1201/9781315152011-3

[30] Iu.I. Ukhanov. Optical properties of semiconductors (Moscow, Nauka, 1977).

[31] M.O. Manasreh. Phys. Rev. B, 53, 16425 (1996). doi: 10.1103/PhysRevB.53.16425

[32] Y. Cai, Y. Liu, Y. Xie, Y. Zou, C. Gao, Y. Zhao, S. Liu, H. Xu, J. Shi, S. Guo, C. Sun. APL Mater., 8, 021107 (2020). doi: $10.1063 / 1.5139664$

[33] F. Litimein, B. Bouhafs, Z. Dridi, P. Ruterana. New J. Phys., 4, 64 (2002). doi: 10.1088/1367-2630/4/1/364

[34] P. Lu, R. Collazo, R.F. Dalmau, G. Durkaya, N. Dietz, Z. Sitar. Appl. Phys. Lett., 93, 131922 (2008). doi: 10.1063/1.2996413

\section{Structural spectroscopic studies of GaN/AIN/Si heterostructures grown by hydride vapour phase epitaxy}

P.V. Seredin ${ }^{1}$, K.A. Barkov' ${ }^{1}$, D.L. Goloshchapov' ${ }^{1}$, A.S. Lenshin ${ }^{1}$, Yu.Yu. Khudyakov ${ }^{1}$, I.N. Arsentiev ${ }^{2}$, A.A. Lebedev', Sh.Sh. Sharofidinov ${ }^{2}$, A.M. Mizerov ${ }^{3}$, I.A. Kasatkin ${ }^{4}$, T. Prutskij ${ }^{5}$

${ }^{1}$ Voronezh State University, 394006 Voronezh, Russia

${ }^{2}$ loffe Institute, 194021 St. Petersburg, Russia

${ }^{3}$ St. Petersburg National Research Academic University of the Russian Academy of Sciences", 194021 St. Petersburg, Russia

${ }^{4}$ St. Petersburg State University, 199034 St. Petersburg, Russia

${ }^{5}$ Instituto de Ciencias,

Benemérita Universidad Autónoma de Puebla, 72050 Puebla, Pue., Mexico

Abstract In this work, we report on the HVPE growth of a GaN film on pretreated $\mathrm{Si}(001)$ silicon substrates through an AlN buffer layer. We demonstrated that the use of the proposed technology led to the formation of a transitional sublayer $\sim 170-200 \mathrm{~nm}$ thick in the Si substrate, further growth on which provided the formation of columnar GaN grains between which there is a thin layer of the AlN phase. The GaN epitaxial film has a low residual stress, which is reflected in the intense luminescence. 